\title{
SEGURIDAD SOCIAL EN EL DEPORTE COLOMBIANO
}

Semillero de Investigacion adscrito al grupo de Investigación SINERGYA (Categoría C Colciencias) de la Facultad de Derecho de la Universidad Surcolombiana.

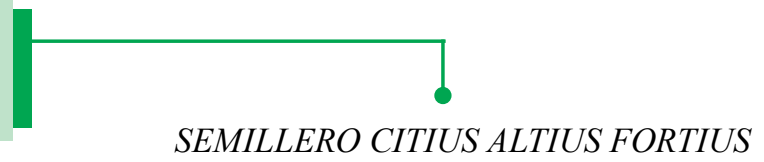

INTEGRANTES

Karen Viviana Santiago, Diego Fernando Chávarro, Sandra Milena Ángel, Edna Tatiana Tafur, Diego Felipe Ortiz.

Docente Tutor: Mg. Efrain Hoyos Galindo

\section{RESUMEN}

La Seguridad Social en el deporte colombiano presenta serios vacíos jurídicos, lo cual ha conllevado al desamparo de la comunidad deportiva en todos los aspectos que comprende el Sistema de Seguridad Social en Colombia: pensión, salud, riesgos profesionales y servicios sociales complementarios. El deportista aficionado no tiene un régimen de seguridad social que lo cobije en ejercicio de su labor deportiva. La anterior necesidad ha sido satisfecha con los seguros estudiantiles, o en su defecto con la afiliación del deportista a una entidad promotora de salud por parte de su familia trabajadora y con ello cotizante. La situación del deportista profesional no es más alentadora, toda vez que éstos cuando ceden sus derechos deportivos al respectivo club, ven desmejorado su derecho fundamental al acceso a la seguridad social, constitucionalmente entendido como un servicio público permanente debido a que no reciben por dicha actividad contraprestación alguna.

\section{PALABRAS CLAVE}

Seguridad Social - Deporte Profesional - Deporte Aficionado - Derechos Deportivos - Glorias del Deporte - Carta de Transferencia - Ligas - Federaciones - Clubes.

\section{ABSTRACT}

The lack of regulations presented by the social security in Colombian sport have leaded not to protect the sport community in all aspects, such as healthy pensions, professional risk, and some others. The player doesn't have social security that covers his job. This necessity has been supplied by student health unsurance or in some cases, the player is joined to another health insurance for being beneficiary of the family and so his family can benefit from this plan as well. A professional player's situation is not encouraged. These entities have not improved the player's rights. Sport club rights which are deterisating his access to security with is know as permanent public services. Due to this fact, they are not viable for some loans.

\section{KEYWORDS}

Social Security - Professional Sport - Amateur Sports - Sports rights - Sports Glorifies Transference Letters - Leagues - Federations - Sports Clubs- 


\section{INTRODUCCIÓN}

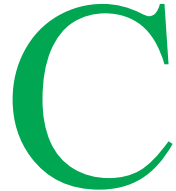
ada día es más apremiante la necesidad de una seguridad social con amplia cobertura entendida como la acción de disponer lo conveniente para atender las necesidades o contingencias previsibles de la sociedad ${ }^{1}$ que deben ser garantizadas por el Estado, en ejecución de su función de otorgar los estándares mínimos para la satisfacción de las necesidades básicas de sus administrados, que actualmente resulta, en especial para la comunidad deportiva esquiva, parcial, excluyente y en las peores circunstancias inexistente.

Durante el estudio de la "Seguridad social en el Deporte" hemos podido constatar la falta de políticas estatales en torno a este tema y el desconocimiento que tiene la clase deportiva sobre el particular. Pero, además, la discriminación existente entre deportistas de alto rendimiento, deportistas profesionales y los rasos que, al fin y al cabo, hacen mayoría.

\section{REGLAMENTACIÓN}

Constitución Política de Colombia artículos 48 derecho a la seguridad social, articulo 53 derecho al trabajador, articulo 52 derecho al deporte y a la recreación. Ley 100 de 1993, "Por la cual se crea el sistema de seguridad social integral y se dictan otras disposiciones" preámbulo, artículos $1,2,3$ y 4 principios generales del sistema de seguridad social integral; 6 objetivos del sistema de seguridad social integral; 7 ámbito de acción; 15 afiliación al sistema general de pensiones; 157 tipos de participantes en el sistema de seguridad social en salud y el artículo 161 deberes de los empleadores.

La Ley 776 de 2002 "Por la cual se dictan normas sobre la organización y administración de prestaciones del sistema general de riesgos profesionales".
El Decreto 1231 de la Ley 185 de 1995, estableció el otorgamiento de estímulos académicos, económicos y de seguridad social para deportistas destacados en el ámbito nacional o internacional. En él se incluyen beneficios de un subsidio oficial hasta por cien salarios mínimos mensuales para la adquisición de vivienda o para adelantar programas académicos de educación, mediante convenios entre Coldeportes, el Icetex y entidades públicas y privadas, entre otros estímulos.

Además, el artículo 45 de la Ley 181 de 1995 fija una pensión vitalicia para las glorias del deporte nacional compatible con cualquiera otra pensión o clase de remuneración, siempre que se cumplan algunos requisitos (medallista olímpico o mundial, entre otras). Y también se extienden estímulos académicos, económicos y de seguridad social a los deportistas.

También en el Decreto 1083 de abril 15 de 1997, se reglamenta la pensión vitalicia para las glorias del deporte nacional ${ }^{2}$, quienes tendrán una pensión vitalicia, equivalente a cuatro salarios mínimos mensuales, siempre y cuando, tenga o no recursos económicos, o sus ingresos sean inferiores a cuatro salarios mínimos legales mensuales, y reunan los siguientes requisitos: sean medallistas en campeonatos oficiales en la máxima categoría, es decir, no es un derecho para los medallistas mundiales infantiles, juveniles o sub 17, 20 o 23 años, lo cual debe ser acreditado por la federación de ese deporte y por el COC; o ser medallista en Juegos Olímpicos, lo cual será acreditado por el COC. Además de lo anetrior debe haber cumplido cincuenta (50) años de edad, o en cualquier edad en caso de haber perdido por lo menos el $50 \%$ de su capacidad laboral. Esta pensión podrá perderla el deportista cuando se demuestre que tenga un ingreso superior a 4 salarios mínimos mensuales legales vigente y por muerte del deportista. Dicho reconocimiento es de carácter insustituible.

El Ministerio de Cultura, en Acuerdo No. 000015 del 01 de Diciembre del 2005, estableció nuevas

1 ENCICLOPEDIA JURÍDICA OMEBA. Tomo XXIII. Ed. Bibliográfica Argentina, Buenos Aires, 1967.

2 Son glorias del deporte nacional quienes hayan sido medallistas en campeonatos mundiales, oficiales o en Juegos Olímpicos. 
directrices para entregar un subsidio oficial a los deportistas nacionales destacados en el ámbito internacional. Allí acordó:

- Otorgar a los medallistas de Juegos Olímpicos, Juegos Paralímpicos, Juegos Sordo Olímpicos y Campeonatos Mundiales, un subsidio oficial hasta por cien (100) salarios mínimos, con cargo al presupuesto de Coldeportes, con destino a la adquisición de vivienda propia o para el pago de derechos de matrícula y pensiones de programas académicos.

- Dicho subsidio se entregará una sola vez al año, de manera individual, por evento y corresponderá a la medalla de mayor valor obtenido, independientemente del número de medallas ganadas por el deportista, primando siempre el resultado de las pruebas individuales sobre las colectivas.

- En las pruebas por equipo de los deportes individuales, el valor del incentivo será distribuido por partes iguales, según el número de integrantes.

- En los deportes de conjunto, el subsidio se entregará a cada deportista de acuerdo con la escala de valores que veremos a continuación:

\section{DEPORTES INDIVIDUALES}

\begin{tabular}{|l|c|c|c|}
\hline \multirow{2}{*}{ EVENTO } & \multicolumn{3}{|c|}{ LOGRO DEPORTIVO (MEDALLA) } \\
\cline { 2 - 4 } & \multicolumn{3}{|c|}{$\begin{array}{c}\text { Asignación Salarios Mínimos } \\
\text { Legales Mensuales Vigentes }\end{array}$} \\
\cline { 2 - 4 } & ORO & PLATA & BRONCE \\
\hline $\begin{array}{l}\text { Juegos Olímpicos, } \\
\text { Paralímpicos y Sordo } \\
\text { Olímpicos }\end{array}$ & 50 & 40 & 35 \\
\hline Mundiales Mayores & 25 & 20 & 15,5 \\
\hline Mundial Sub 23 - Juvenil & 15 & 12,5 & 7,5 \\
\hline
\end{tabular}

DEPORTES DE CONJUNTO

\begin{tabular}{|c|c|c|c|}
\hline \multirow{3}{*}{ EVENTO } & \multirow{2}{*}{\multicolumn{3}{|c|}{$\begin{array}{c}\text { LOGRO DEPORTIVO (MEDALLA) } \\
\text { Asignación Salarios Mínimos } \\
\text { Legales Mensuales Vigentes }\end{array}$}} \\
\hline & & & \\
\hline & ORO & PLATA & BRONCE \\
\hline Olímpicos, & & & \\
\hline $\begin{array}{l}\text { Paralímpicos y Sordo } \\
\text { Olímpicos }\end{array}$ & 100 & 80 & 60 \\
\hline Mundiales Mayores & 50 & 40 & 35 \\
\hline Mundial Sub 23 - Juvenil & 30 & 25 & 15 \\
\hline
\end{tabular}

3 CARREÑO, Álvaro, Manual De Derecho y Gestión Deportiva, pág. 96.

4 Ley 181 de 1995 Art. 16
Tal como se ve, las disposiciones y las buenas intenciones son muchas, pero la verdad es que son muy pocas las que se están desarrollando y se aplican, en unos casos por la falta de recursos económicos y en otros porque se afectan otras disposiciones o políticas administrativas, que los hacen vacías o nugatorias. ${ }^{3}$

A pesar de estar debidamente reglamentados, alguno de los estímulos y beneficios en seguridad social, no existen como mecanismo expedito para que el deportista una vez gane tenga acceso al mismo. Así mismo, mucho de los premios que se ganan con el esfuerzo de toda una vida de entrenamientos, figuran como obra de la buena voluntad del mandatario de turno, convirtiendo el acto en favor político mas no en política pública .

\section{SEGURIDAD SOCIAL EN EL DEPORTE AFICIONADO}

El Deporte Aficionado es aquel que no admite pago o indemnización alguna a favor de los jugadores o competidores, distinto del monto de los gastos efectivos ocasionados durante el ejercicio de la actividad deportiva correspondiente ${ }^{4}$.

En el deporte aficionado no hay mayores estímulos en cuanto a la seguridad social. No existe un régimen de pensiones ni un seguro de enfermedad que lo cobije. Existe la idea de que sólo cuando el deportista logra un alto nivel competitivo el Estado entra a sufragar una serie de gastos para el presente y el futuro (como educación, remuneración, asistencia médica, concentraciones, alimentación, alojamiento, viajes a competencias, etc.).

Las ligas no tienen recursos para asegurar a todos sus deportistas, pero sí hay unos recursos que asume el Estado a través de programas de apoyo a deportistas de alto rendimiento que cubren accidentes e invalidez, sin llegar a convertirse en pensión. Pero si un deportista no es medallista, 
parece no tener derecho a casi nada; para ello es necesario aclarar que la obligación en salud no corresponde a ligas ni federaciones porque éstas no son empresas promotoras de trabajo. De ahí que cuando existe alguna vinculación diferente a la de simple competencia entre los deportistas y las ligas, ésta funciona con gran flexibilidad pues dichas labores no son reconocidas como contratos (no incluyen seguridad y desconocen las prestaciones sociales).

Es una constante que el deportista de un grupo familiar que trabaja, este afiliado a alguna entidad promotora de salud. Pero si la cabeza de familia no labora, no hay seguridad social. En este caso, los estratos uno y dos, acuden al SISBÉN (Sistema de Identificación de Beneficiarios Potenciales para Programa Sociales). En cuanto a pensiones, tampoco existen programas aunque se debería tener uno semejante al de la jubilación. Llegamos a la conclusión que para que un joven se dedique a la práctica competitiva del deporte, su grupo familiar debe afiliarlo como beneficiario o si trabaja, como cotizante.

El papel de la empresa privada es vital. En Colombia apenas se dan pasos, aunque muy importantes, con algunas empresas que dan toda clase de seguridad social a los deportistas, incluso en algunas oportunidades se les vincula también a programas de pensiones, pero todo ello con el ánimo de lograr los incentivos tributarios que ofrece la normatividad cuando se invierte en la promoción del deporte.

En Colombia hay cerca de 40 pensionados del deporte (reciben $\$ 1.200 .000$ mensuales). También, a algunos de los llamados pioneros se les dio, por una vez, un apoyo económico (\$15 millones) ${ }^{5}$.

\section{SEGURIDAD SOCIAL EN EL PROFESIONALISMO}

El Deporte Profesional es el que admite como competidores a personas naturales bajo remuneración, de conformidad con las normas de la respectiva federación internacional ${ }^{6}$.

En el ámbito deportivo nacional, el deporte de mayor desarrollo, reconocimiento y práctica, es el fútbol. Por esto, se hará énfasis en él para destacar las relaciones que se desarrollan entre jugadores y clubes empleadores, las cuales deben tener como base fundamental la existencia de un contrato de trabajo.

Para poder interpretar y darle contenido a las diferentes prácticas utilizadas por los clubes de fútbol profesional cuando vinculan un jugador de fútbol profesional a su institución acudiremos a nuestra legislación laboral, pues es a través del derecho, particularmente el derecho laboral, que se pretende transformar la práctica del deporte en una actividad digna.

Durante muchos años se le ha denominado derechos deportivos, a aquella facultad exclusiva que tienen los clubes empleadores de registrar, inscribir y autorizar la actuación de un jugador, cuya carta de transferencia fuera de su propiedad (del club). Estos derechos deportivos son objeto de acuerdos económicos entre clubes deportivos para efecto de transferencias o préstamo de jugadores. La carta de transferencia corresponde al medio de prueba documental donde consta que los derechos deportivos pertenecen a un determinado club $^{7}$.

Por mucho tiempo los derechos deportivos han servido para que un jugador se traslade de un club a otro, pero no existía suficiente claridad con respecto al tema del vínculo

5 SERIES EL COLOMBIANO, Area Deportiva. "El deporte "profesión” con muy poco amparo". Medellín, Colombia 2007.

$6 \quad$ Ley 181 de 1995 Art. 16.

7 Corte Constitucional, Sala Plena, Bogotá, 3 de julio de 1997, M.P. Alejandro Martínez Caballero, Sentencia C-320 de 1997. 
que unía un jugador con su club empleador. Esto dio paso a que se presentaran abusos por parte de los clubes empleadores, quienes sin tener un contrato vigente con el jugador, no permitían que el jugador llegara a un acuerdo económico con otro club y que fuera a jugar libremente con aquel, apoyándose en la idea de que el club que ostentare los derechos deportivos, independientemente de que existiere contrato de trabajo o no, podía decidir la suerte del jugador.

No obstante, gracias a los pronunciamientos de la Corte Constitucional, en primer lugar se logró acabar con la exclusividad en cabeza de los clubes para ser titulares de los derechos deportivos de los jugadores y en segundo lugar estableció que sin contrato de trabajo vigente, no podrían existir derechos deportivos. Sin embargo continúa siendo un obstáculo el hecho de no haber removido por completo de la ley, la noción de derechos deportivos que se mantiene ${ }^{8}$, y que a su vez se encuentra contenida en el Estatuto del Jugador de la Federación Colombiana de Fútbol' ${ }^{9}$.

En la sentencia C-320 de 1997, la Corte Constitucional consagra la figura de los derechos deportivos, determina que no hay lugar a ellos mientras no medie un contrato de trabajo entre el jugador y el club empleador ${ }^{10}$. A partir de este fallo, la noción de derechos deportivos al estar supeditada a la existencia de un contrato de trabajo, no podrá ser utilizada por un club empleador para impedir que un jugador sin contrato de trabajo vigente, pueda celebrar un nuevo contrato con otro club distinto, pues se tendrá únicamente en cuenta que el contrato que lo unía con su último club hubiera terminado. De ésta manera un jugador que termine su contrato queda en libertad de negociar uno nuevo con el club que quiera, sin que se deba compensación alguna por concepto de derechos deportivos.

En consecuencia, el contrato de trabajo constituirá la única fuente de derechos y obligaciones entre las partes y pone fin a la posibilidad de que los derechos deportivos sean utilizados como mecanismo de retención del jugador por parte de su club empleador.

Anteriormente los derechos deportivos representaban un activo para el club, y como un activo podía venderse y recibir una retribución a cambio y precisamente por eso, si quien estuviere interesado en adquirir los derechos deportivos del jugador no cancelaba el precio fijado por el club titular, el jugador nunca tendría la oportunidad de cambiar de club. Al instaurarse un régimen basado exclusivamente en contratos de trabajo, la libertad de contratación del jugador se ve plenamente garantizada. Igualmente, los clubes no dejarán de percibir compensaciones por los jugadores formados en su institución, toda vez que el Reglamento sobre el Estatuto y la transferencia de Jugadores FIFA, establece el pago de una indemnización a favor del club o clubes formadores del jugador, que deberá ser pagado por el nuevo club a donde vaya el jugador. También se estableció en dicho reglamento, un mecanismo de solidaridad que consiste en el reconocimiento del $5 \%$ de lo que perciba el club o clubes formadores del jugador, por las indemnizaciones recibidas, diferentes a la indemnización por formación, por la transferencia de un jugador que tuviere contrato vigente.

De esta forma se garantiza, tanto la libertad del jugador para contratar con un nuevo club al finalizar su contrato, como las compensaciones a que haya lugar a favor de un club por la transferencia de jugadores.

Para que los deportistas puedan acceder a un sistema de seguridad social, tienen que comenzar por asociarse para garantizar su futuro, pero no lo hacen por ignorancia, porque no conocen los beneficios y derechos que tienen, les falta voluntad y decisión. Consideramos que así como los clubes deportivos disponen de los derechos

$8 \quad$ Ley 181 de 1995 art. 34

9 Estatuto del Jugador Colfútbol art. 21

10 Corte Constitucional,Sentencia C-320 de 1997, Bogotá, 3 de julio de 1997, M.P. Alejandro Martínez Caballero. 
deportivos de los jugadores a ellos vinculados, estos mismos en contraprestación deberían garantizar los elementos propios del Sistema General de Seguridad Social: salud, pensión, riesgos profesionales y servicios sociales complementarios. Bajo éste supuesto podemos concluir que ${ }^{11}$ :

1. La mayoría de deportistas profesionales en Colombia son víctimas del incumplimiento de la Ley 100 de 1993 que consagra el derecho de la seguridad social integral del trabajador.

2. Algunos equipos de fútbol en Colombia, de la primera y segunda división, no cumplen siquiera con afiliación de sus deportistas a una EPS, a pesar de que constantemente viajan y están sometidos a muchos riesgos.

3. Aunque los deportistas han tomado conciencia y conocen más del tema, todavía existen temores por demandar porque en Colombia los dirigentes los vetan y les cierran las puertas, terminando así con carreras brillantes.

\section{UN CASO PARA ANALIZAR}

"Nunca llegó a maldecir, ni siquiera en los momentos más duros cuando ya el cáncer le había arrebatado las cuerdas bucales y su garganta estaba destrozada luego de 25 radioterapias y cinco quimioterapias. No podía hablar, ni siquiera pasar un bocado de comida. Juan Diego Giraldo Covaleda siempre se mantuvo firme pensando en un futuro que él mismo sabía, no existía para él.

El gigantesco luchador antioqueño, de 1.87 metros, 34 años, 104 kilos de peso y esporádicamente practicante de sumo, murió en la madrugada del un 4 de febrero. Desangrado, como testifica su hermana Sara, porque ya no había más nada qué hacer: el tumor maligno se lo llevó.

Se fue vestido con una sudadera de Antioquia, la misma que llevó con orgullo durante tanto tiempo y en sus manos una medalla de las muchas que le colgaron en su cuello durante 19 años de labor deportiva. Sólo eso. Aquí dejó uno que otro uniforme, un cúmulo de medallas, trofeos y placas, recortes de prensa, álbumes con fotografías. Y nada más porque ni siquiera sus dos pequeños hijos, Juan Diego, de cinco años, y Jacobo Andrés, de uno, quedaron con un futuro asegurado.

En vida, Juan Diego y su familia no contaron con el dinero suficiente para afiliarse a algún servicio de salud. No lo tuvo como contribuyente porque su única "profesión" conocida era la práctica del deporte (aficionado). Tampoco como vinculado porque aunque dependía de la familia materna, quienes laboraban eran sus hermanos y ninguno tenía capacidad económica para responder por los demás. Y cuando logró el beneficio de esa asistencia, en calidad de subsidiado, adscrito al Sisbén, fue demasiado tarde.

Hoy, quienes lidiaron su caso por más de dos años, desde cuando comenzó a presentar los síntomas mortales del cáncer que le sobrevino al complicársele una mordida de lengua cuando entrenaba en el módulo de lucha, ven con incredulidad y desconocimiento cómo Juan Diego dejó desamparados a sus dos hijos.

Cero pensión, cero seguridad, porque como ciudadano común y corriente nunca pudo acceder a ese servicio pese a que según reza la Constitución, "todo colombiano tiene derecho a la salud". Y como practicante de un deporte mucho menos porque ni clubes, ni ligas, ni federaciones, que a su vez se benefician de aquellos, están en la obligación de brindar seguridad social". ${ }^{2}$

\section{SEGURIDAD SOCIAL EN EL PROCESO DE FORMACIÓN DEPORTIVO}

Los deportistas empiezan con el proceso de formación deportivo desde su base, es decir, en el colegio o la escuela, luego aparecen aquellos de barriada, para más allá darle paso a los asociados

11 SERIES EL COLOMBIANO, Area Deportiva. "El deporte "profesión" con muy poco amparo". Medellín, Colombia 2007.

12 DIAZ SÁNCHEZ, Wilson. SERIES EL COLOMBIANO, "Profesionales en alto riesgo". Medellín, Colombia 2007. 
a clubes, afiliados a ligas $\mathrm{y}$, por consiguiente, acogidos por programas de federaciones, hasta llegar al profesionalismo siempre y cuando el deporte tenga ese rango.

En la primera instancia, la seguridad social que se brinda a los muchachos, está representada por los seguros estudiantiles que exige cada institución y que cobija lesiones y enfermedades. Esos mismos beneficios son aprovechados por clubes, ligas y federaciones a la hora de llegar esos deportistas a la competencia organizada, porque no hay una ley que obligue a estas entidades a brindar ese servicio. Pero cuando el deportista no es estudiante, ni tiene trabajo remunerado o su familia no está en capacidad de sostenerle una afiliación a los regímenes de salud, una EPS o un Sisbén, queda desamparado y cruzando dedos para evitar que su salud no se resquebraje.

De acuerdo con la ley que rige para el marco colombiano, todo accidente que ocurre, tanto en el entrenamiento como en la competencia, y nos referimos al caso específico de los equipos profesionales, es calificado como de trabajo. Sin embargo en el deporte aficionado no opera esta figura, configurándose de esta manera una clara violación de sus derechos fundamentales.

\section{EL ACCIDENTE DEPORTIVO COMO RIESGO PROFESIONAL}

Es accidente de trabajo todo suceso repentino que sobrevenga por causa o con ocasión del trabajo y que produzca en el trabajador una lesión orgánica, una perturbación funcional, una invalidez o la muerte. ${ }^{13}$

El principio general indica que los eventos donde se produzcan accidentes con ocasión de la actividad deportiva no son accidentes de trabajo. ${ }^{14}$ El empleador no contrata gente para hacer deporte o recrearse, salvo que esa sea su actividad.

Los accidentes que se presenten en desarrollo de las actividades deportivas sólo serán calificados como accidente de trabajo cuando el evento se realice por cuenta o en representación del empleador:

Por cuenta: El empleador asume todos los riesgos del evento, desde la selección, el entrenamiento, el reglamento, las sanciones, etc.

En representación: En este caso el empleado va a la actividad cumpliendo una orden del empleador para representarlo en un evento, allí también asumirá los riesgos

El empleador es responsable de la prevención de riesgos de sus trabajadores. ${ }^{15}$ Un empleador responsable sólo asume como profesionales los eventos deportivos o culturales sobre los cuales tenga total control en su administración y prevención de riesgos. Asumir como profesional cualquier evento deportivo recreativo o cultural implica una clara responsabilidad del empleador o el administrador que lo supone.

\section{COMPARANDO CON OTROS PAÍSES}

En Francia, Alemania y Cuba, por citar algunos, el Estado tiene un sistema de protección no sólo contra riesgos provenientes de la actividad física sino también de los que tienen que ver con salud y pensiones por años de servicio, retiro y vejez ${ }^{16}$. En Colombia no hay nada de eso. El deportista común y corriente si no está adscrito a algún sistema de salud y pensiones, no podrá tener acceso a este fundamental derecho, debido a que ninguna entidad -llámese Liga, Federación, Coldeportes o Comité Olímpico Colombiano-, le subvencionará dicho servicio.

13 Decreto 1295 de 1994, Art. 9. 
En España, existe un convenio especial para deportistas de alto nivel que permite la inclusión en el Régimen Especial de Trabajadores por Cuenta Propia o Autónomos a los deportistas de alto nivel, mayores de dieciocho años que, en razón de su actividad deportiva o de cualquier otra actividad profesional que realicen no estén ya incluidos en cualquiera de los Regímenes del Sistema de la Seguridad Social ${ }^{17}$.

\section{CONCLUSIONES}

El deportista es el único "empleado" en Colombia que no goza de una estabilidad laboral y por consiguiente tampoco de sus beneficios, a pesar de que el deporte está catalogado como una actividad económica, pues la actividad deportiva se encuentra registrada en el Sistema General de Riesgos Profesionales con el Riesgo 1 Código 9241-01 en la codificación de Salud Ocupacional. Los empleadores no tienen en cuenta ésta afiliación y por lo tanto no cumplen con las obligaciones allí contempladas; por ello es necesario que el mismo deportista conozca esta reglamentación para con ello poder exigir su cumplimiento ${ }^{18}$.

Pero tal vez el factor más preocupante para que no haya una reglamentación efectiva al respecto, es el económico. ¿Cuánto le costaría al Estado afiliar a todos los deportistas a los sistemas de seguridad social? ¿Cómo haría una Liga para asegurar a sus practicantes si a duras penas subsiste con presupuestos de funcionamiento irrisorios?

En Colombia, contrariamente a lo que sucede en naciones más adelantadas, estos exponentes que dejan en alto el nombre deportivo de una región, un departamento o el país, reciben poco a cambio.
Existen algunos programas de apoyo al deportista, encabezados por el Comité Olímpico Colombiano y Coldeportes Nacional, con miras a competencias mundiales u olímpicas, pero sólo dedican su atención a una minoría, precisamente porque se cree que la seguridad social es necesaria cuando el deportista logra un alto nivel competitivo, quienes se benefician de convenios interinstitucionales, por ejemplo, para la educación y pueden recibir alguna remuneración económica. Allí es donde el Estado entraría a sufragar los gastos para el presente y el futuro; pero si un deportista no es medallista, no tiene derecho a casi nada.

Ante esto, los deportistas colombianos han optado por agremiarse, para así poder acceder a los beneficios de la seguridad social en salud, pensiones, y servicios complementarios. Ejemplo de ello es el equipo de fútbol de la ciudad de Medellín el Atletico Nacional, que es modelo en organización en este aspecto, pues además de tener inscrito a todo su plantel a una EPS, ofrece un subsidio de medicina prepagada. Igualmente existe un contrato con una aseguradora de riesgos profesionales y cada jugador elige, al momento de estampar su firma, el fondo de pensiones que más le llene sus expectativas.

Finalmente tendríamos que dejar en claro que las enfermedades que se derivan de los riesgos a que se somete el deportista ya sea mediante un vínculo profesional o simplemente aficionado, durante su tiempo de práctica, deben ser consideradas como verdaderas enfermedades profesionales. Para ello consideramos que sería pertinente añadir en la legislación deportiva, nuevas normas que contribuyan a vigilar $\mathrm{y}$ sancionar a los clubes, ligas y federaciones que incumplan con los deberes consagrados en la Ley 100 de 1993, en lo concerniente a la seguridad social de los deportistas.

17 MINISTERIO DE TRABAJO Y SEGURIDAD SOCIAL. DECRETO NÚMERO 1607 DE 2002, Por el cual se modifica la Tabla de Clasificación de Actividades Económicas para el Sistema General de Riesgos Profesionales y se dictan otras disposiciones. Riesgo 1. Código 924101 empresas dedicadas a actividades deportivas y otras actividades de esparcimiento, incluye centros y/o clubes sociales y deportivos.

18 Artículo 27 de la Orden TAS/2865/2003, de 13 de octubre y el Real Decreto 1467/1997 de 19 de septiembre, España. 


\section{ANEXO}

EXTRACTO DE LA SENTENCIA C-393 DEL 23 DE MAYO DE 2007

Demanda de inconstitucionalidad en contra de los Artículos 6, 10 y 11 (parciales) de la Ley 789 de 2002.

ACTOR: Juan Carlos Cortés González

TEMA: Subsidio de Desempleo al Deportista

MAGISTRADO PONENTE: Dr. Manuel José Cepeda Espinosa

TEXTO DE LA NORMA ACUSADA: LEY 789 DE 2002, por la cual se dictan normas para apoyar el empleo y ampliar la protección social y se modifican algunos artículos del Código Sustantivo de Trabajo:

\section{ARTÍCULO 6o. RECURSOS PARA} EL FOMENTO DEL EMPLEO Y PROTECCIÓN AL DESEMPLEO.

Las Cajas de Compensación Familiar administrarán en forma individual y directa o asociada con otra u otras Cajas un fondo para apoyar al empleo y para la protección al desempleado conforme los artículos $7^{\circ}, 10 \mathrm{y}$ 11 de la presente ley. El Gobierno determinará la forma en que se administrarán estos recursos cuando no puedan ser gestionados directamente por la Caja de Compensación Familiar.

"Las Cajas apropiarán de los recursos del fondo, por cada beneficiario de los programas de subsidio de que trata la presente ley, un monto per cápita que será definido en enero de cada año por la Superintendencia del Subsidio, de acuerdo con los beneficios que se deben otorgar, en concordancia con la presente ley. Las apropiaciones del monto per cápita se realizarán en la medida en que se produzcan las solicitudes de subsidios hasta agotar los recursos propios de cada Caja. No obstante, para garantizar la solidaridad y el equilibrio ante la diferente situación de desempleo y recursos disponibles entre las distintas Cajas del país, mínimo semestralmente la Superintendencia realizará cortes contables y ordenará el traslado de recursos entre Cajas, de acuerdo con el monto per cápita requeridas para los desempleados pendientes en unas Cajas, en estricto orden de solicitud, y los recursos sobrantes en otras. Igual procedimiento se aplicará para el apoyo a los desempleados sin vinculación anterior a las Cajas de Compensación de acuerdo con el porcentaje previsto para tal efecto en esta ley.

"ARTÍCUlO 10. RÉGIMEN DE APOYO PARA DESEMPLEADOS CON VINCULACIÓN ANTERIOR A LAS CAJAS DE COMPENSACIÓN

\section{FAMILIAR.}

Los Jefes cabeza de Hogar que se encuentren en situación de desempleo luego de haber estado vinculados al sistema de Cajas de Compensación Familiar no menos de 1 año dentro de los tres años anteriores a la solicitud de apoyo, tendrán derecho con cargo a los recursos del fondo para el fomento del empleo y la protección del desempleo de que trata el artículo $6^{\circ}$ de la presente ley a los siguientes beneficios, por una sola vez y hasta que se agoten los recursos del fondo. La reglamentación establecerá los plazos y condiciones a partir de los cuales se reconocerá este subsidio:

a) Un subsidio equivalente a un salario y medio mínimo legal mensual, el cual se dividirá y otorgará en seis cuotas mensuales iguales, las cuales se podrán hacer efectivas a través de aportes al sistema de salud, y/o bonos alimenticios y/o educación, según la elección que haga el beneficiario. Para efectos de 
esta obligación las cajas destinarán un máximo del $30 \%$ de los recursos que les corresponde administrar con cargo al fondo para el fomento del empleo y la protección del desempleo;

b) Capacitación para el proceso de inserción laboral. Para efectos de esta obligación las Cajas destinarán un máximo del veinticinco por ciento (25\%) de los recursos que les corresponde administrar con cargo al fondo para el fomento al empleo y protección al desempleo.

\section{"ARTÍCULO 11. RÉGIMEN DE APOYO PARA DESEMPLEADOS SIN VINCULACIÓN ANTERIOR A CAJAS DE COMPENSACIÓN FAMILIAR.}

Con cargo al cinco por ciento (5\%) del fondo para el fomento del empleo y la protección del desempleo de que trata el artículo $6^{\circ}$ de la presente ley, las Cajas establecerán un régimen de apoyo y fomento al empleo para jefes cabeza de hogar sin vinculación anterior a las Cajas de Compensación Familiar, que se concretará en un subsidio equivalente a un salario y medio mínimo legal mensual, el cual se otorgará en seis cuotas mensuales iguales, las cuales se podrán hacer efectivas a través de aportes al sistema de salud, o bonos alimenticios o educación, según la elección que haga el beneficiario. Tendrán prioridad frente a las Cajas de Compensación Familiar, los artistas, escritores y deportistas afiliados a las correspondientes asociaciones o quienes acrediten esta condición en los términos en que se defina por el Gobierno Nacional. Para acceder a esta prestación, se deberá acreditar falta de capacidad de pago, conforme términos y condiciones que disponga el reglamento en materia de organización y funcionamiento de este beneficio." (Se subrayan los apartes demandados).

\section{Consideraciones del actor:}

Estima el actor que la disposición acusada es violatoria de los artículos 1,13 y 48 de la Constitución Política, porque la Ley 789 de 2002, distingue dos clases de personas desempleadas: las vinculadas anteriormente a una caja de compensación familiar y los que no estaban vinculadas con anterioridad a ellas. Y que contempla que un grupo especial de desempleados, compuesto por artistas, deportistas y escritores, tendrá prioridad en la asignación de los subsidios. Por lo cual las disposiciones atacadas enmarcan un tratamiento discriminatorio carente de proporcionalidad y razonabilidad en sentido de que ordena dársele prioridad - esto es, se les reconocerá el subsidio al desempleo sin consideración al turno según el momento de radicación de las solicitudes por sobre el turno de otros desempleados (aún con posibles mayores cargas familiares) que con anterioridad radicaron su solicitud en el grupo de los desempleados sin vinculación anterior al sistema de subsidio familiar, a los artistas, escritores y deportistas, quienes gozan de un privilegio en la asignación de los recursos para subsidios, sin que dicho tratamiento se soporte justificadamente en un criterio proporcional y necesario que permita una discriminación positiva.

\section{Consideraciones de la Corte Constitucional.}

La Corte considera que el trato prioritario establecido en la norma es constitucional, porque se trata de proteger grupos tradicionalmente marginados y con más dificultades de reintegrarse al mercado laboral. Así, estiman que la medida constituye una aplicación del art. 13 de la Constitución, que impone la protección especial de los grupos marginados como una acción afirmativa en beneficio de quienes se encuentran expuestos a mayores vulnerabilidades. 
Además, porque la cultura y el deporte constituyen actividades que fueron valoradas de manera especial por el Constituyente. Ello justifica que se preste una particular atención a las personas que se dedican al ejercicio de esas actividades. Pero, además, el mismo artículo 11 dispone que el subsidio se brindará a los jefes cabeza de hogar que acrediten su "falta de capacidad de pago." Es decir, el subsidio no se entregará a los artistas, los escritores y los deportistas que dispongan en su hogar de los medios suficientes para subsistir. Él se brinda únicamente a las personas dedicadas a la cultura y el deporte que, a pesar de sus difíciles condiciones económicas y sabedoras de que muy frecuentemente la sociedad no valora debidamente su trabajo, persisten en su dedicación a estas actividades. Es decir, tal como lo plantean los intervinientes, el subsidio se brindaría a un grupo social que se encuentra frecuentemente al margen de las actividades económicas ordinarias de la sociedad, a pesar de la importancia de su labor para la comunidad.

Decisión: Declarar la EXEQUIBILIDAD de los cargos analizados.

\section{BIBLIOGRAFÍA}

ARIAS ESPINOSA, Rafael Enrique y TAMAYO IANNINI, Andrés. "La crisis de la noción de derechos deportivos y primacía del contrato de trabajo en el vínculo entre jugadores de futbol profesional y clubes empleadores". Bogotá D.C. 2006. Pontificia Universidad Javeriana, Facultad de Ciencias Jurídicas - Derecho.

SERIES EL COLOMBIANO. "El deporte, "profesión” con muy poco amparo". Medellín -Colombia, 2007.

DÍAZ SANCHEZ, Wilson. SERIES EL COLOMBIANO. "Profesionales en alto riesgo”. Medellín-Colombia, 2007.
BUSTAMANTE, Oswaldo. SERIES EL COLOMBIANO. "Programas alternativos, solución para una élite". Medellín-Colombia, 2007.

CORTE CONSTITUCIONAL, Sentencia C-393 DE 2007. M.P. Juan Carlos Cortés Gonzales. (23 de mayo).

MINISTERIO DE CULTURA, Acuerdo $\mathrm{N}^{\circ}$ 000015 del 01 de Diciembre de 2005.

CARREÑO CARREÑO, Álvaro. "Manual de Derecho y Gestión Deportiva”, Bogotá, Colombia, 2004.

Decreto 1231 de la Ley 185 de 1995

Ley 181 de 1995. "Ley del Deporte"

Decreto 1083 de abril 15 de 1997 